\title{
Anomalous Origin of the Right Coronary Artery Diagnosed by CARdiac Computed Tomography
}

\author{
Siva K. Kumar, MD, Faisal Shaikh, MD, Paul J. Mather, MD
}

\section{Case Presentation}

A 34 year old female with no significant past medical history presented with intermittent left shoulder and chest pain. The pain was burning in nature over her left chest and radiated to her left arm. There were no alleviating or exacerbating factors. Initial electrocardiogram showed sinus bradycardia. Cardiac computed tomography angiography revealed anomalous origin of the right coronary artery, which arises from the left sinus of Valsalva (Figure 1) and then travels towards the right side between the pulmonary outflow tract and the aortic root, where it shows mild narrowing of about $50 \%$, (Figure 2) for a length of approximately $1 \mathrm{~cm}$. The woman performed 9 mets during her exercise stress nuclear test which demonstrated electrocardiographic evidence of ischemia with normal myocardial perfusion.

\section{Discussion}

Cardiac ischemia in this setting is presumed to be caused by compression of the anomalous right coronary artery (RCA) as it courses between the PA and the aorta during exercise. Coronary artery anomalies are noted on approximately $1.3 \%$ of all cardiac catheterizations. ${ }^{1}$ Anomalous origin of the RCA from the left sinus of Valsalva has been reported in approximately 0.03$0.09 \%$ of patients undergoing coronary angiography. Although previously considered to be a rare, but benign anomaly, more recently it has been associated with myocardial ischemia, infarction and sudden death in up to $30 \%$ of patients. ${ }^{1-7}$ Patients may be at risk for premature atherosclerosis. In the setting of an obstructive lesion, these vessels are amenable to successful

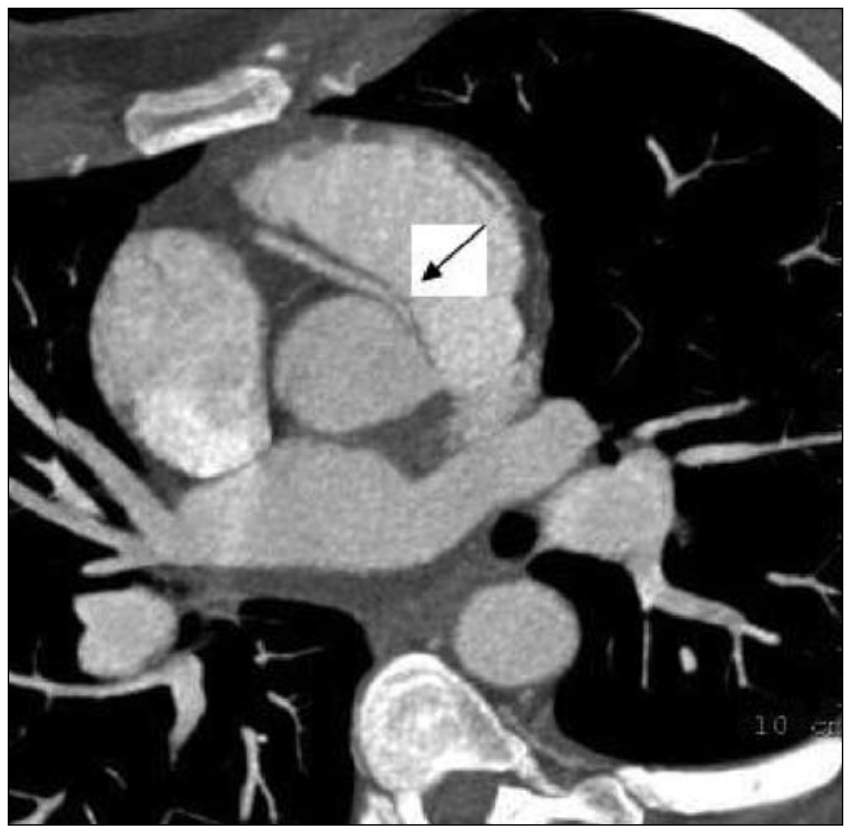

Figure 1.

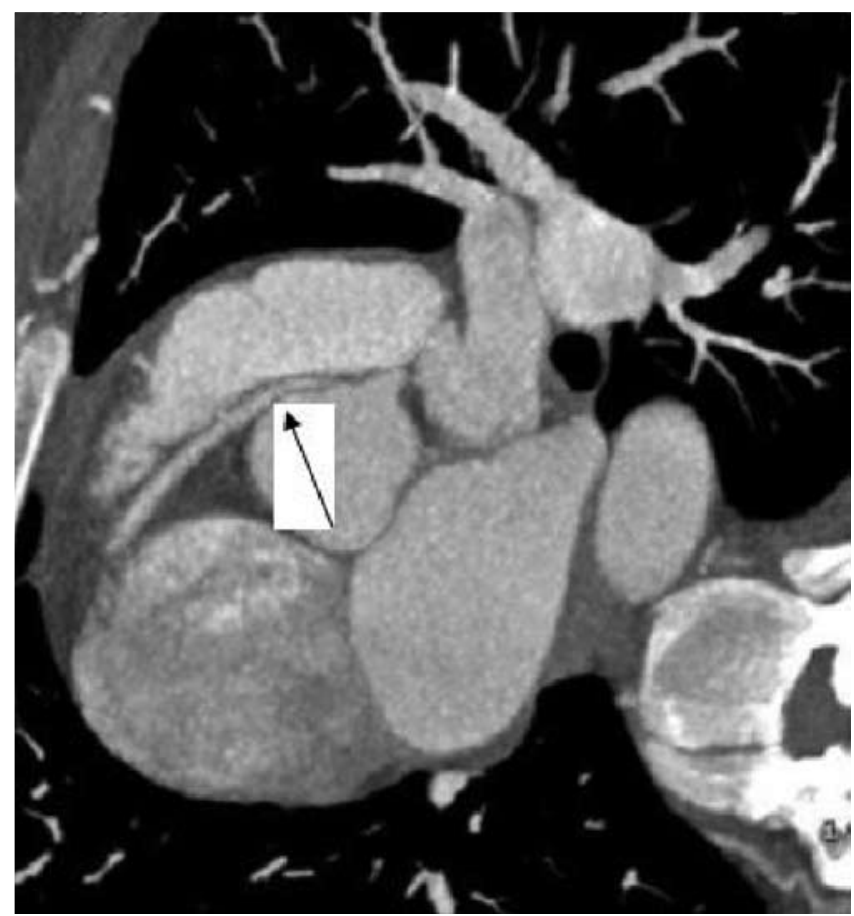

Figure 2.

percutaneous coronary intervention and stent placement. ${ }^{8}$ The patient has been asymptomatic for the past year while being treated with beta blockers.

\section{References}

1. Yamanaka O, Hobbs RE. Coronary artery anomalies in 126595 patients undergoing coronary angiography. Catheter Cardiovasc Diagn 1990;21:28 -40.

2. Engel HJ, Torres C, Page HL. Major variations in anatomical origin of the coronary arteries: angiographic observations in 4250 patients without associated congenital heart disease. Catheter Cardiovasc Diagn 1975;1:157 -69.

3. Basso C, Maron BJ, Corrado D, Thiene G. Clinical profile of congenital coronary artery anomalies with origin from the wrong aortic sinus leading to sudden death in young competitive athletes. J Am Coll Cardiol 2000;35:1493-501.

4. Roberts WC, Siegel RJ, Zipes DP. Origin of the right coronary artery from the left sinus of Valsalva with associated chest pain: report of two cases. Cathet Cardiovasc Diagn 1976; 2:397.

5. Taylor AJ, Rogan KM, Virmani R. Sudden cardiac death associated with isolated congenital coronary artery anomalies. J Am Coll Cardiol 1992; 20: 640-647

6. Isner JM, Shen EM, Martin ET et al: Sudden unexpected death as a result of anomalous origin of the right coronary artery from the left sinus of Valsalva. Am J Med. 1984 Jan;76 (1) 155-158.

7. Angelini P, Velasco JA, Flamm S. Coronary anomalies: Incidence, pathophysiology, and clinical relevance. Circulation 2002;105:2449-2454.

8. Cohen MG, Tolleson TR, Peter RH, Harrison JK, Sketch MH Jr. Successful percutaneous coronary intervention with stent implantation in anomalous right coronary arteries arising from left sinus of vaslsalva: a report of two cases. Catheter Cardiovascular Intervention. 2002 Jan;55(1):105-8. 